\title{
An Analytic Approach to Capillary Pressure in Tree-Shaped Networks
}

\author{
A.F. Miguel* \\ Department of Physics and Geophysics Centre of Évora, University of Évora, Portugal
}

\begin{abstract}
This study analyzes the pressure in capillary tree-shaped networks, based on the thermodynamics and the geo metric description of the network. The presence of equilibrium and non-equilibrium effects on pressure is accounted. In particular, the presence of equilibrium effects is shown to be essential for describing the pressure in the network. An approach to the definition of equilibrium capillary pressure is presented in terms of interfacial energies of the phases but also in terms of the geometry characteristics of the tree-shaped network. Among others, the equilibrium capillary pressure is shown to depend on number of branching levels and number of daughter branches. Finally, a criterion is established to evaluate the importance of equilibrium and non-equilibrium effects on the capillary pressure.
\end{abstract}

\section{INTRODUCTION}

The study of capillary-driven flows is a subject of great interest due to its widespread applications in oil recovery, hydrology, catalysis, membranes, among others [1]. The dynamic invasion of fluid into a capillary tube was first studied analytically by [2] and [3]. The so-called LucasWashburn equation describes the time penetration of liquid into a capillary. While this approach holds promise for describing the long-time capillary flow, it neglects the influence of the forces that prevail in the initial stage of the flow. Other authors [4,5] studied the thermodynamic and kinetic effects on capillary penetration in systems of limited size. In addition, Ichikawa and Satoda [6] characterized the interface dynamics of capillary flow. The capillary rise dominated by inertial forces was investigated by [7], and Zhmud et al. [8] presented an overview of the solutions for the different time regimes. Other authors, Siebold et al. [9] and Chan et al. [10] have performed capillary experiments to study the effect of the dynamic contact angle and to determine the factors that influence the significance of gravity, respectively. Raiskinmaki et al. [11] included the effect of entrance pressure loss on the capillary driven flow. An approach that accounts for non-equilibrium effects on capillary pressure was proposed by [12]. Others [13] developed a model for the capillary rise in porous media which incorporates dynamic saturation gradients in the media. Based on experiments, Cheng et al. [14] showed a connection between the capillary pressure and the fluid interfacial area in porous media. Other studies [15] extended the equilibrium capillary pressure based on the first law of thermodynamics to a fractal porous media. The dynamic capillary rise due to hydrostatic effects was studied by [16].

Research on tree-shaped capillary networks, though dating back one century [17], is still a topic of great interest due to its widespread applications in physics, biology, geology and engineering. The simulation of fluid flow through these structures requires an accurately knowledge of the

*Address correspondence to this author at the Department of Physics and Geophysics Centre of Évora, University of Évora, Portugal;

E-mail:afm@uevora.pt pressure distribution of a fluid through the structure. Studies performed in porous media point out the dependence of capillary pressure on the rate change of moisture inside the media, suggesting that departures from equilibrium are dependent on the movement of fluid interfaces (see for example, Beliaeve and Hassanizadeh [12], Deinert et al. [15] and Fan et al. [18]). Therefore, capillary pressure is an essential quantity that deserves further analysis.

Here we focus on tree-shaped networks. The interest in tree-shaped flow networks is spreading through different fields. Trees for cooling in electronics were studied by $[19,20]$. Applications for single-phase flow and two-phase flow have been proposed by $[19,21,22]$. Concepts for treeshaped heat and mass exchangers were proposed by Coppens et al. [23] and Tondeur et al. [24].

This paper combines the thermodynamics and geometric characteristics of the system to describe capillary pressure in tree-shaped networks. Based on the approach developed, the non-equilibrium and equilibrium effects on the capillary pressure are identified. Besides, the equilibrium capillary pressure is defined in terms of readily measurable parameters. The influence of geometric parameters of the treeshaped network is studied to obtain a better understanding of this quantity.

\section{TREE-SHAPED NETWORKS:}

\section{Geometric and Operational Parameters}

The geometric parameters of the tree-shaped network are defined in Fig. 1. This network has $\mathrm{N}$ branches of ducts, from level 0 to level $\mathrm{n}$. Each duct branches into $\mathrm{m}$ daughter branches at the next level. The ducts are round capillary tubes of different radii $\left(R_{i}\right)$ and lengths $\left(L_{i} ; i=0,1, \ldots, n\right)$. The radii and lengths of the ducts are sized relative to one another, in accordance with $[17,25,26]$ :

$$
\begin{aligned}
\frac{\mathrm{R}_{\mathrm{i}}}{\mathrm{R}_{\mathrm{i}+1}} & =\mathrm{a}_{\mathrm{r}} \\
\frac{\mathrm{L}_{\mathrm{i}}}{\mathrm{L}_{\mathrm{i}+1}} & =\mathrm{b}_{1}
\end{aligned}
$$


where $a_{r}$ and $b_{1}$ are scale factors independent of $i$. The relationship between the size of the first duct (level 0) and the size of the ducts at level $i$ is given by

$$
\begin{aligned}
& \frac{\mathrm{R}_{\mathrm{i}}}{\mathrm{R}_{0}}=\mathrm{a}_{\mathrm{r}}{ }^{\mathrm{i}} \\
& \frac{\mathrm{L}_{\mathrm{i}}}{\mathrm{L}_{0}}=\mathrm{b}_{1}{ }^{\mathrm{i}}
\end{aligned}
$$

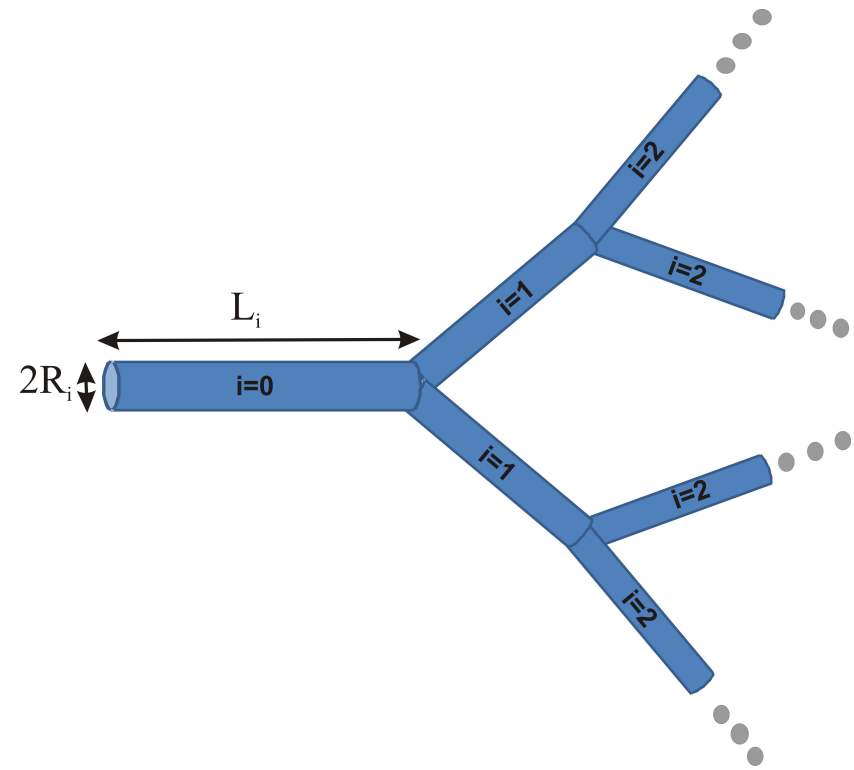

Fig. (1). Tree-shaped capillary network $(\mathrm{N}=3 ; \mathrm{m}=2)$.

One basic feature of tree-shaped networks is that pairing, or bifurcation of ducts (dichotomy), is an optimized feature of the flow architecture (see for example [17,25]). Therefore, $\mathrm{m}$ takes a value of 2 . If the flow is laminar and fully developed, the minimization of flow resistance yields the scale factor $\mathrm{a}_{\mathrm{r}}=2^{-1 / 3}$, which in physiology is known as Hess-Murray law [26]. Moreover, for bifurcations $(\mathrm{m}=2)$ the scale factors $\mathrm{b}_{1}$ and $\mathrm{a}_{\mathrm{r}}$ range from $2^{-1}$ to $2^{-1 / 3}$, respectively. If the flow is turbulent, $a_{\mathrm{r}}$ and $b_{1}$ are $2^{-3 / 7}$ and $2^{-1 / 7}$, respectively [25]. In both flows it seems that is a geometric ratio of $\mathrm{R} / \mathrm{L}^{3}$ which is preserved.

The total number of branches is

$$
\mathrm{N}=\sum_{\mathrm{i}=0}^{\mathrm{n}} \mathrm{m}^{\mathrm{i}}=\frac{1-\mathrm{m}^{\mathrm{q}}}{1-\mathrm{m}}
$$

with $\mathrm{q}=\mathrm{n}+1$ and the volume of the whole network is

$$
\mathrm{V}_{\mathrm{s}}=\sum_{\mathrm{i}=0}^{\mathrm{n}} \mathrm{m}^{\mathrm{i}} \alpha_{\mathrm{vs}} \mathrm{R}_{\mathrm{i}}^{2} \mathrm{~L}_{\mathrm{i}}
$$

where $\alpha_{v s}$ is a shape factor (i.e., $\pi$ ). Substituting Eqs. (3) and (4) into (6) we obtain

$$
\begin{aligned}
& \mathrm{V}_{\mathrm{s}}=\alpha_{\mathrm{vs}} \mathrm{R}_{0}^{2} \mathrm{~L}_{0} \sum_{\mathrm{i}=0}^{\mathrm{n}} \mathrm{m}_{\mathrm{r}}^{\mathrm{i}} \mathrm{a}_{\mathrm{r}}^{2 \mathrm{i}} \mathrm{b}_{1}^{\mathrm{i}}= \\
& =\alpha_{\mathrm{vs}} \mathrm{R}_{0}^{2} \mathrm{~L}_{0} \frac{1-\left(\mathrm{ma}_{\mathrm{r}}^{2} \mathrm{~b}_{1}\right)^{\mathrm{q}}}{1-\mathrm{ma}_{\mathrm{r}}^{2} \mathrm{~b}_{1}}
\end{aligned}
$$

In a similar procedure, the surface area is
$A_{s}=\sum_{i=0}^{n} m^{i} \alpha_{a s} R_{i} L_{i}=\alpha_{a s} R_{0} L_{0} \frac{1-\left(m a_{r} b_{1}\right)^{q}}{1-m a_{r} b_{1}}$

Here $\mathrm{m}$ is the number of branches, $\mathrm{n}$ is the final branching level and $\alpha_{a s}$ is a shape factor (e.g., $\pi$ ). Equations (7) and (8) show the volume and the surface area of the treeshaped network in terms of the geometric characteristics of the first duct, number of branches and scale factors.

\section{CAPILLARY PRESSURE:}

\section{Thermodynamic Model}

We assume a wetting fluid entering in a capillary tube under a pressure $\mathrm{p}_{\mathrm{w}}$, and that this fluid distributes itself by displacing a non-wetting fluid at pressure $\mathrm{p}_{\mathrm{n}}$. The first law of thermodynamics, for the system under study, can be mathematically expressed by [27]

$$
\dot{\mathrm{U}}=\mathrm{F} \dot{\mathrm{r}}+\sum_{\mathrm{j}} \zeta_{\mathrm{w}, \mathrm{j}} \dot{\mathrm{A}}_{\mathrm{w}, \mathrm{j}}-\mathrm{p}_{\mathrm{w}} \dot{\mathrm{V}}_{\mathrm{w}}-\mathrm{p}_{\mathrm{n}} \dot{\mathrm{V}}_{\mathrm{n}}+\mathrm{T} \dot{\mathrm{S}}
$$

where $\mathrm{U}$ is the internal energy of the fluid, $\mathrm{T}$ is the fluid temperature, $V_{w}$ is the volume of wetting fluid, $V_{n}$ is the volume of non-wetting fluid, $\mathrm{A}$ is the interfacial area of the fluid, $\mathrm{S}$ is the entropy of the fluid, $\zeta$ is the interfacial energy of the wetting fluid in contact with the $i$ non-wetting phase and the first right-hand term denotes the power done by force $\mathrm{F}$ to move the solid-fluid interfaces.

Consider a slow, capillary-driven flow under isothermal conditions. Under these conditions, it is reasonable to consider that the internal energy and the entropy of the fluid are

constant [15]. Therefore, as $\dot{V}_{w}+\dot{V}_{n}=0$, Eq. (9) can be written as

$$
\mathrm{P}_{\mathrm{c}} \dot{\mathrm{V}}_{\mathrm{w}}=\left(\mathrm{p}_{\mathrm{n}}-\mathrm{p}_{\mathrm{w}}\right) \dot{\mathrm{V}}_{\mathrm{w}}=-\mathrm{Fr}-\sum_{\mathrm{j}} \zeta_{\mathrm{w}, \mathrm{j}} \dot{\mathrm{A}}_{\mathrm{w}, \mathrm{j}}
$$

In summary, Eq. (10) shows how the capillary pressure $\mathrm{P}_{\mathrm{c}}$ results of the motion of the solid-fluid interfaces (nonequilibrium effect), as well as of the interfacial energy of the wetting fluid in contact with the non-wetting phases and the fluid interfacial area (equilibrium effect).

According to $[15,18]$ the first right-hand term of Eq. (10) is related to the contact line velocity and the volume of wetting fluid. Therefore, Eq. (10) can be rearranged to yield

$$
P_{c}=-\mu \frac{\partial}{\partial t}\left(\frac{V_{w}}{V}\right)-\sum_{j} \zeta_{w, j}\left(\frac{\partial A_{w, j}}{\partial V}\right)_{U, S, T}
$$

where $\mu$ is a coefficient that accounts for the movement of fluid-solid contact lines and $\mathrm{V}_{\mathrm{W}} / \mathrm{V}$ is the moisture content. Therefore, the first right-hand term accounts for the nonequilibrium effects (i.e., the change of fluid-solid contact lines and the change of moisture content in time), and the second right-hand term accounts for the change of interfacial areas with fluid volume (equilibrium effects)

$$
\mathrm{P}_{0}=-\sum_{\mathrm{j}} \zeta_{\mathrm{w}, \mathrm{j}}\left(\frac{\partial \mathrm{A}_{\mathrm{w}, \mathrm{j}}}{\partial \mathrm{V}}\right)_{\mathrm{U}, \mathrm{S}, \mathrm{T}}
$$


Equation (12) represents the so-called equilibrium capillary pressure $[15,18]$ and shows that this pressure depends both on the interfacial energy of the wetting fluid and on the variation in fluid interfacial areas with respect to fluid volume. Therefore, it is also a function of network's saturation. These results are in agreement with several studies (see for example $[12,15,18,28])$, which recognize that the interfaces play a key role in describing the multiphase fluid flow.

\section{EQUILIBRIUM FLUID PRESSURE IN A TREE- SHAPED NETWORK}

Consider a tree-shaped network as shown as in Fig. 1. In order to obtain the equilibrium capillary pressure, we must provide the variation in fluid interfacial area with fluid (network) volume. Therefore, a description of the geometry of the network is required.

Consider a two-phase flow where a liquid (e.g., water, wetting phase) displaces air (non-wetting phase) in a treeshaped network. To implement Equation (12) we need to determine $\partial \mathrm{A} / \partial \mathrm{V}$ and this can be obtained from the geometry of the tree-shaped network. In a similar procedure to that described above, the interfacial area with corresponding pore volume for a situation where a liquid displaces air are expressed as

$$
\begin{aligned}
& A_{a}=\sum_{i=0}^{n} m^{i} \alpha_{a a} R_{i}^{2}=\alpha_{a a} R_{0}^{2} \frac{1-\left(m a_{r}^{2}\right)^{q}}{1-m a_{r}^{2}} \\
& V_{a}=\sum_{i=0}^{n} m^{i} \alpha_{v a} R_{i}^{3}=\alpha_{v a} R_{i}^{3} \frac{1-\left(m a_{r}^{3}\right)^{q}}{1-m a_{r}^{3}}
\end{aligned}
$$

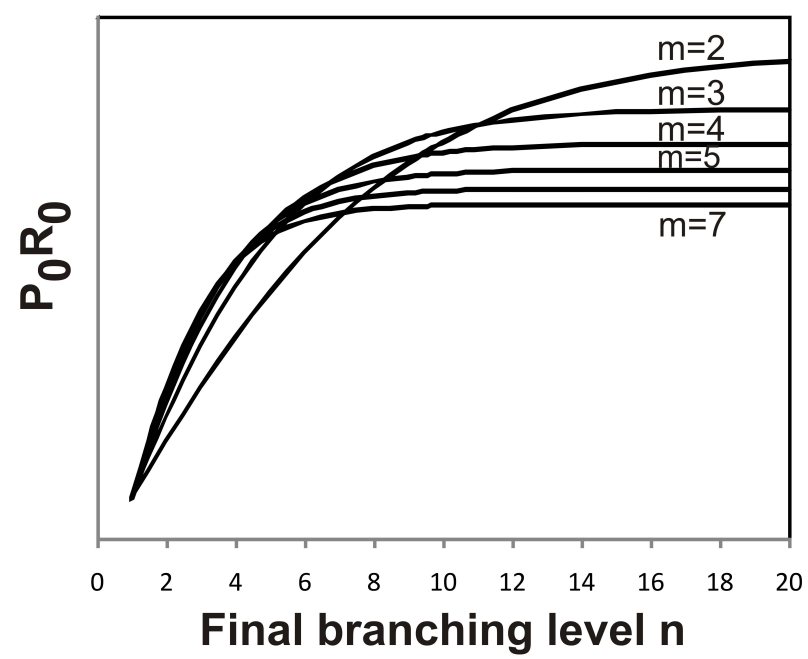

Fig. (2). Dependence of $\mathrm{P}_{0} \mathrm{R}_{0}$ on branching level $\mathrm{n}$ for different number of daughter branches $\mathrm{m}$.

Here the subscript a means air, and $\alpha_{\mathrm{aa}}$ and $\alpha_{\mathrm{va}}$ are shape factors (e.g., $4 \pi$ and $4 / 3 \pi$ for a spherical interface, respectively). Therefore, according to Equations (7) and (8) and Equations (13) and (14), the derivatives $\partial \mathrm{A} / \partial \mathrm{V}$ are given by

$$
\begin{aligned}
& \frac{\partial \mathrm{A}_{\mathrm{w}, \mathrm{s}}}{\partial \mathrm{V}}=\frac{\partial \mathrm{A}_{\mathrm{w}, \mathrm{s}}}{\partial \mathrm{R}_{0}}\left(\frac{\partial \mathrm{V}}{\partial \mathrm{R}_{0}}\right)^{-1}= \\
& \frac{\chi_{\mathrm{s}}}{\mathrm{R}_{0}}\left[\frac{1-\left(\mathrm{ma}_{\mathrm{r}} \mathrm{b}_{1}\right)^{\mathrm{q}}}{1-\mathrm{ma}_{\mathrm{r}} \mathrm{b}_{1}}\right]\left[\frac{1-\mathrm{ma}_{\mathrm{r}}^{2} \mathrm{~b}_{1}}{1-\left(\mathrm{ma}_{\mathrm{r}}^{2} \mathrm{~b}_{1}\right)^{\mathrm{q}}}\right] \\
& \frac{\partial \mathrm{A}_{\mathrm{w}, \mathrm{a}}}{\partial \mathrm{V}_{\mathrm{a}}}=\frac{\partial \mathrm{A}_{\mathrm{w}, \mathrm{a}}}{\partial \mathrm{R}_{0}}\left(\frac{\partial \mathrm{V}_{\mathrm{a}}}{\partial \mathrm{R}_{0}}\right)^{-1}= \\
& \frac{\chi_{\mathrm{a}}}{\mathrm{R}_{0}}\left[\frac{1-\left(\mathrm{ma}_{\mathrm{r}}^{2}\right)^{\mathrm{q}}}{1-\mathrm{ma}_{\mathrm{r}}^{2}}\right]\left[\frac{1-\mathrm{ma}_{\mathrm{r}}^{3}}{1-\left(\mathrm{ma}_{\mathrm{r}}^{3}\right)^{\mathrm{q}}}\right]
\end{aligned}
$$

with $\chi_{\mathrm{s}}=(1 / 2) \alpha_{\mathrm{as}} / \alpha_{\mathrm{vs}}$ and $\chi_{\mathrm{a}}=(2 / 3) \alpha_{\mathrm{aa}} / \alpha_{\mathrm{va}}$. Substituting Eqs. (15) and (16) into Eq. (12) yields

$$
\mathrm{P}_{0}=-\frac{\left(\eta_{\mathrm{w}, \mathrm{s}}+\eta_{\mathrm{w}, \mathrm{a}}\right)}{\mathrm{R}_{0}}
$$

with

$$
\begin{aligned}
& \eta_{\mathrm{w}, \mathrm{s}}=\chi_{\mathrm{s}} \zeta_{\mathrm{w}, \mathrm{s}}\left[\frac{1-\left(\mathrm{ma}_{\mathrm{r}} \mathrm{b}_{1}\right)^{\mathrm{q}}}{1-\mathrm{ma}_{\mathrm{r}} \mathrm{b}_{1}}\right]\left[\frac{1-\mathrm{ma}_{\mathrm{r}}^{2} \mathrm{~b}_{1}}{1-\left(\mathrm{ma}_{\mathrm{r}}^{2} \mathrm{~b}_{1}\right)^{\mathrm{q}}}\right] \\
& \eta_{\mathrm{w}, \mathrm{a}}=\chi_{\mathrm{a}} \zeta_{\mathrm{w}, \mathrm{a}}\left[\frac{1-\left(\mathrm{ma}_{\mathrm{r}}^{2}\right)^{\mathrm{q}}}{1-\mathrm{ma}_{\mathrm{r}}^{2}}\right]\left[\frac{1-\mathrm{ma}_{\mathrm{r}}^{3}}{1-\left(\mathrm{ma}_{\mathrm{r}}^{3}\right)^{\mathrm{q}}}\right]
\end{aligned}
$$

Equation (17) presents the equilibrium capillary pressure in terms of the radius of the first duct $\left(\mathrm{R}_{0}\right)$, scale factors $\left(\mathrm{a}_{\mathrm{r}}\right.$, $\left.b_{1}\right)$, branches characteristics $(m, n)$, shape factors $\left(\chi_{\mathrm{a}}, \chi_{\mathrm{s}}\right)$ and interfacial energies $\left(\zeta_{\mathrm{w}, \mathrm{a}}, \zeta_{\mathrm{w}, \mathrm{s}}\right)$ of the respective phase. Equation (17) is also dependent of the network's saturation. For a saturated network

$$
\mathrm{P}_{0, \text { sat }}=\frac{\chi_{\mathrm{s}} \zeta_{\mathrm{w}, \mathrm{s}}}{\mathrm{R}_{0}}\left[\frac{1-\left(\mathrm{ma}_{\mathrm{r}} \mathrm{b}_{1}\right)^{\mathrm{q}}}{1-\mathrm{ma}_{\mathrm{r}} \mathrm{b}_{1}}\right]\left[\frac{1-\mathrm{ma}_{\mathrm{r}}^{2} \mathrm{~b}_{1}}{1-\left(\mathrm{ma}_{\mathrm{r}}^{2} \mathrm{~b}_{1}\right)^{\mathrm{q}}}\right]
$$

Based on this formulation, we were able to research some aspects concerning the parameters that affect the equilibrium capillary pressure. The results are plotted in Figs. 2 to 4.

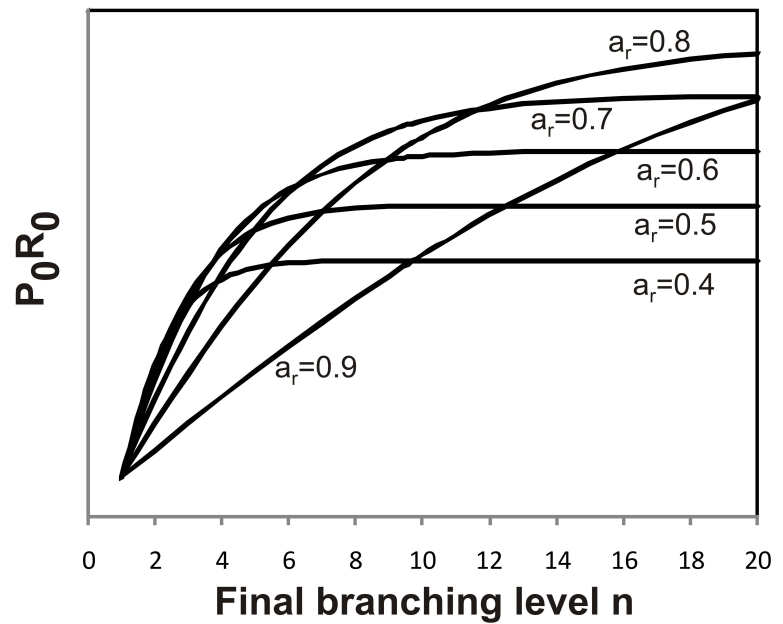

Fig. (3). Dependence of $\mathrm{P}_{0} \mathrm{R}_{0}$ on branching level $\mathrm{n}$ for different scale factors $a_{r}\left(m=2 ; b_{1}=2^{-1}\right)$. 
Fig. (2) shows the effect of the branching level and the number of daughter branches on equilibrium capillary pressure. According to this figure, we come to the conclusion that the $\mathrm{P}_{0} \mathrm{R}_{0}$ is strongly dependent on $\mathrm{n}$ and $\mathrm{m}$. Besides, for $\mathrm{n} \leq 6$ the pairing, or bifurcation of ducts $(\mathrm{m}=2)$ generates the lowest equilibrium capillary pressure. On the other hand, for $\mathrm{n} \geq 12$ a network with bifurcating ducts has the highest equilibrium capillary pressure if compared with higher number of daughter branches. For each $m$ there is a certain value of $n$ for which increasing the level of branching do not affect the equilibrium capillary pressure. This is reached first (i.e., at lower branching levels $\mathrm{n}$ ) for higher number of daughter branches.

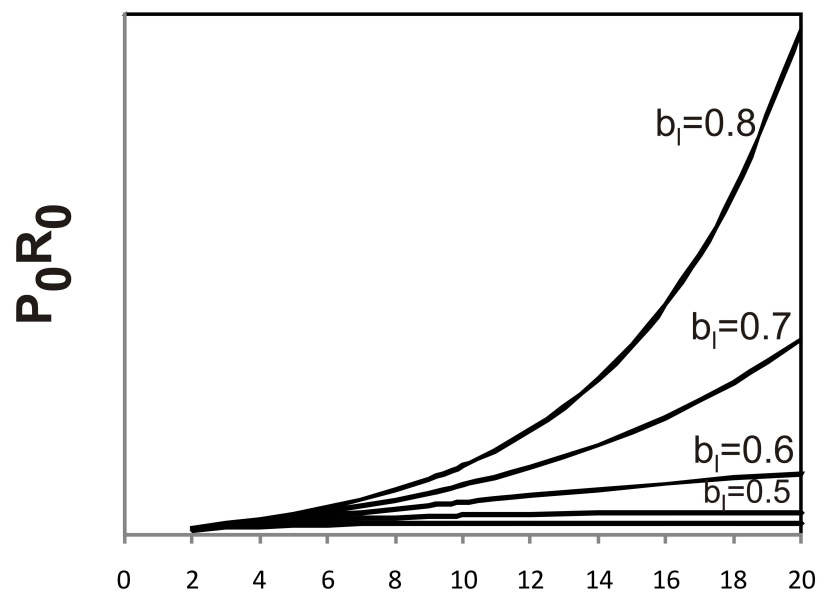

Final branching level $\mathbf{n}$

Fig. (4). Dependence of $\mathrm{P}_{0} \mathrm{R}_{0}$ on branching level $\mathrm{n}$ for different scale factors $b_{1}\left(m=2 ; a_{r}=2^{-1 / 3}\right)$.

The effects of scale factor $a_{r}$ and $b_{1}$ are presented in Figs. (3) and (4). Fig. (3) reveals that when the scale factor $a_{r}$ increases, the maximum equilibrium capillary pressure occurs at higher branching levels $\mathrm{n}$. Besides, for each $\mathrm{a}_{\mathrm{r}}$ there is a certain value of $\mathrm{n}$ for which increasing the level of branching do not affect the equilibrium capillary pressure. This value of $n$ is reached first for lower values of $a_{r}$. Fig. (4) indicates that the equilibrium capillary pressure becomes higher at high scale factor $b_{1}$, which is an expected result since an higher scale factor provides a longer network.

At this stage, it is also possible to establish a criterion to evaluate the importance of equilibrium and non-equilibrium effects on the capillary pressure. According to Eqs. (11) and (17), the equilibrium pressure is dominant when

$$
\frac{1}{\mathrm{R}_{0}}>\frac{\mu}{\eta_{\mathrm{w}, \mathrm{a}}+\eta_{\mathrm{w}, \mathrm{s}}} \frac{\partial}{\partial \mathrm{t}}\left(\frac{\mathrm{V}_{\mathrm{w}}}{\mathrm{V}}\right)
$$

The equilibrium capillary pressure persists in time as the main driving potential, as long as the geometry of the network obeys this criterion (Eq. 21).

\section{CONCLUDING REMARKS}

Capillary fluid flow has been the focus of many studies because of its importance in nature and in different complex flow structures. This study focused on the understanding of capillary pressure in a tree-shaped network. An approach is presented by combining the thermodynamics and the geometric description of the tree-shaped network. The nonequilibrium effects of the capillary, arising from forces acting on the fluid-solid contact line, are compared with the equilibrium effects determined by the change in interfacial areas with fluid volume. Finally, an approach is presented whereby equilibrium capillary pressure is shown to be related with the geometry of the network.

\section{ACKNOWLEDGEMENT}

This work has been partially supported by the Portuguese National Science Foundation (FCT) under contract no. POCTI/EME/59909/2004.

\section{NOMENCLATURE}

$\begin{array}{lll}\mathrm{A} & = & \text { Interfacial area of the fluid } \\ \mathrm{a}_{\mathrm{r}} & = & \text { Scale factors for radius } \\ \mathrm{b}_{\mathrm{l}} & = & \text { Scale factors for length } \\ \mathrm{F} & = & \text { Force to move the solid-fluid interfaces } \\ \mathrm{L} & = & \text { Duct length } \\ \mathrm{m} & = & \text { Number of branches } \\ \mathrm{N} & = & \text { Branches of ducts } \\ \mathrm{n} & = & \text { Final branching level } \\ \mathrm{p}_{\mathrm{n}} & = & \text { Pressure of non-wetting fluid } \\ \mathrm{p}_{\mathrm{w}} & = & \text { Pressure of wetting fluid } \\ \mathrm{R}_{0} & = & \text { Duct radius of the first duct (level 0) } \\ \mathrm{R} & = & \text { Duct radius } \\ \mathrm{S} & = & \text { Fluid entropy } \\ \mathrm{T} & = & \text { Fluid temperature } \\ \mathrm{U} & = & \text { Fluid internal energy } \\ \mathrm{V}_{\mathrm{n}} & = & \text { Volume of non-wetting fluid } \\ \mathrm{V}_{\mathrm{w}} & = & \text { Volume of wetting fluid } \\ \mathrm{V}_{\mathrm{W}} / \mathrm{V} & = & \text { Moisture content }\end{array}$

\section{Greek symbols}

$\zeta=$ Interfacial energy of the wetting fluid in contact with the non-wetting phase

$\alpha_{\mathrm{a}} \quad=\quad$ Shape factor for area

$\alpha_{\mathrm{v}} \quad=\quad$ Shape factor for volume

$\mu \quad=\quad$ Coefficient that accounts for the movement of fluid-solid contact lines

\section{REFERENCES}

[1] P. Capek, V. Hejtmánek, L. Brabec, A. Zikánová, M. Kocirík, "Network modelling of capillary pressure curves, permeability, and diffusivity, “ Chem. Eng. Sci., vol. 62, pp. 5117-5122, Sept. 2007.

[2] R. Lucas, "Ueber das Zeitgesetz des kapillaren Aufstiegs von Flussigkeiten," Kolloid Z., vol. 23, pp. 15-22, 1918

[3] E. W. Washburn, "The dynamics of capillary flow," Phys. Rev., vol. 21, pp. 273-283, March 1921

[4] A. Marmur, "Penetration and displacement in capillary systems of limited size," Adv. Colloid Interface Sci., vol. 39, pp. 13-33, April 1992 
[5] A. Marmur, R. D. Cohen, "Characterization of porous media by the kinetics of liquid penetration: the vertical capillaries model," $J$. Colloid Interface Sci., vol. 189, pp. 299-304, May 1997.

[6] N. Ichikawa, Y. Satoda, "Interface dynamics of capillary flow in a tube under negligible gravity condition," J. Colloid Interface Sci., vol. 162, pp. 350-355, Feb. 1994.

[7] D. Quéré, "Inertial capillarity", Europhys. Lett., vol. 39, pp. 533538, Sept. 1997.

[8] B. V. Zhmud, F. Tiberg, K. Hallstensson, "Dynamics of capillary rise," J. Colloid Interface Sci., vol. 228, pp. 263-269, Aug. 2000.

[9] A. Siebold, M. Nardin, J. Schultz, A. Walliser, M. Oppliger, "Effect of dynamic contact angle on capillary rise phenomena," Colloids Surf. A, vol. 161, pp. 81-87, Jan. 2000.

[10] T. Y. Chan, C. S. Hsu, S. T. Lin, "Factors affecting the significance of gravity on the infiltration of a liquid into a porous solid," J. Porous Mater., vol. 11, pp. 273-237, Oct. 2004.

[11] P. Raiskinmaki, A. S. Manesh, A. Jasberg, A. Kaponen, J. Merikoski, J. Timonen, "Lattice-Boltzmann simulation of capillary rise dynamics,” J. Stat. Phys., vol. 107, pp. 143-158, April 2002.

[12] A. Y. Beliaev, S. M. Hassanizadeh, "A theoretical model of hysteresis and dynamic effects in the capillary relation for two-phase flow in porous media," Transport Porous Med., vol. 43, pp. 487510, June 2001.

[13] D. A. Lockington, J. Y. Parlange, "A new equation for macroscopic description of capillary rise in porous media," J. Colloid Interface Sci., vol. 278, pp. 404-409, Oct. 2004.

[14] J. T. Cheng, L. J. Pyrak-Nolte, D. D. Nolte, N. J. Giordano, "Linking pressure and saturation through interfacial areas in porous media," Geophys. Res. Lett., vol. 31, pp. 22, Oct. 2004

[15] M. R. Deinert, J. Y. Parlange, K. B. Cady, "Simplified thermodynamic model for equilibrium capillary pressure in a fractal porous medium," Phys. Rev. E, vol. 72, pp. 041203, Oct. 2005

[16] H. T. Xue, Z. N. Fang, Y. Yang, J. P. Huang, L. W. Zhou, “Contact angle determined by spontaneous dynamic capillary rises with hydrostatic effects: experiment and theory," Chem. Phys. Lett., vol. 432, pp. 326-330, Dec. 2006.
[17] A. Bejan, I. Dincer, S. Lorente, A. F. Miguel, A. H. Reis, Porous and Complex Flow Structures in Modern Technologies. New York: Springer, 2004.

[18] L. Fan, H. Fang, Z. Lin, "Simulation of contact line dynamics in a two-dimensional capillary tube by the lattice Boltzmann model," Phys. Rev. E, vol. 63, pp. 051603, May 2001.

[19] D. V. Pence, "Reduced pumping power and wall temperature in microchannel heat sinks with fractal-like branching channel networks," Microscale Thermophys. Eng., vol. 6, pp. 319-30, Jan. 2002.

[20] Y. Chen, P. Cheng, "Heat transfer and pressure drop in fractal treelike microchannel nets," Int. J. Heat Mass Trans., vol. 45, pp. 2643-2648, June 2002.

[21] A. Bejan "Dendritic constructal heat exchanger with small-scale crossflows and larger-scales counterflows," Int. J. Heat Mass Tran., vol. 45, pp. 4607-4620, Nov. 2002.

[22] C. Zamfirescu, A. Bejan, "Constructal tree-shaped two-phase flow for cooling a surface,” Int. J. Heat Mass Trans., vol. 46, pp. 2785 2797, July 2003.

[23] M. O. Coppens, Y. Cheng, C. M. van den Bleek, "Controlling fluidized bed operation using a novel hierarchical gas injection system," in AIChE Annual Meeting, Dallas, 1999, paper 304d

[24] D. Tondeur, L. Luo, D. D'Ortona, “Optimisation des transferts et des materiaux par l'approche constructale," Entropie, vol. 30, pp. 32-37, June 2000.

[25] A. Bejan, Shape and Structure - from Engineering to Nature. Cambridge. Cambridge: University Press, 2000

[26] E. Weibel, Symmorphosis: on form and function in shaping life. Cambridge Massachusetts: Harvard University Press, 2000.

[27] A. F. Miguel, "Contribution to flow characterisation through porous media,” Int. J. Heat Mass Trans., vol. 43, pp. 2267-2272, July 200 .

[28] W. G. Gray, S. M. Hassanizadeh, "Unsaturated flow theory including interfacial phenomena," Water Resour. Res., vol. 27, pp.18551863, April 1991.

(C) A.F. Miguel; Licensee Bentham Open.

This is an open access article distributed under the terms of the Creative Commons Attribution License (http://creativecommons.org/licenses/by/2.5/), which permits unrestrictive use, distribution, and reproduction in any medium, provided the original work is properly cited. 